\title{
Inducible Inactivation of Hepatic LRP Gene by Cre-mediated Recombination Confirms Role of LRP in Clearance of Chylomicron Remnants
}

\author{
Astrid Rohlmann, ${ }^{\star}$ Michael Gotthardt, ${ }^{\S}$ Robert E. Hammer, ${ }^{\ddagger}$ and Joachim Herz ${ }^{\star}$ \\ $*$ Department of Molecular Genetics and ${ }^{\ddagger}$ Department of Biochemistry, University of Texas Southwestern Medical Center, Howard \\ Hughes Medical Institute, Dallas, Texas 75235; and ${ }^{\S}$ Max-Delbrück-Center, Berlin, Germany
}

\begin{abstract}
The multifunctional low density lipoprotein (LDL) receptor-related protein (LRP) has been postulated to participate in a number of diverse physiological and pathological processes ranging from the homeostasis of plasma lipoproteins, atherosclerosis, and fibrinolysis to neuronal regeneration and survival. It has not been possible to demonstrate in vivo the physiological significance of LRP for each of these complex processes by a conventional gene knockout approach because LRP is essential for embryonic development. Here we have used the Cre/loxP recombination system to achieve inducible, tissue-specific and quantitative disruption of the LRP gene in adult mice. Inactivation of LRP in the livers of LDL receptor-deficient mice resulted in the accumulation of cholesterol-rich remnant lipoproteins in the circulation. In normal animals, this caused a compensatory upregulation of the LDL receptor in the liver. Conditional gene targeting has thus allowed us to isolate a specific physiological function of LRP for in vivo analysis and has provided unequivocal evidence for another LDL receptor-independent cholesterol clearance pathway in liver. (J. Clin. Invest. 1998. 101: 689-695.) Key words: Cre recombinase - low density lipoprotein • homologous recombination • chylomicron remnant • cholesterol metabolism
\end{abstract}

\section{Introduction}

The removal of large cholesterol-rich lipoproteins containing apoB from the circulation takes place primarily in the liver and is mediated by at least two endocytic receptors, the LDL receptor and the LDL receptor-related protein (LRP). ${ }^{1}$ The LDL receptor binds apoB100 as well as apoE. A genetic defect in the LDL receptor is the underlying cause for familial hypercholesterolemia in which the apoB100 containing LDL frac-

Address correspondence to Joachim Herz, Department of Molecular Genetics, UT Southwestern Medical Ctr., 5323 Harry Hines Blvd., Dallas, TX 75235-9046. Phone: 214-648-5633; FAX: 214-648-8804; E-mail: herz@utsw.swmed.edu

Received for publication 18 July 1997 and accepted in revised form 17 December 1997.

1. Abbreviations used in this paper: GAPDH, glyceraldehyde-3-phosphate dehydrogenase; HSPGs, heparan sulfate proteoglycans; LRP, LDL receptor-related protein.

J. Clin. Invest.

(C) The American Society for Clinical Investigation, Inc. 0021-9738/98/02/0689/07 \$2.00

Volume 101, Number 3, February 1998, 689-695

http://www.jci.org tion in plasma is dramatically increased (1). In contrast, the clearance of apoB48/apoE containing chylomicron remnants which carry dietary cholesterol from the gut to the liver is not affected in this disease in humans $(2)$ and animals $(3,4)$ that are homozygous for an LDL receptor gene defect.

Much circumstantial evidence, obtained in vitro as well as in vivo, suggests that the alternative pathway by which chylomicron remnants are taken up by hepatocytes is in fact a complex process involving hepatic lipase (5), cell surface heparan sulfate proteoglycans (HSPGs) $(6,7)$, cell surface bound apoE $(8,9)$, and the LRP (10-12). A currently accepted model states that chylomicrons, after having been converted to remnants by the action of lipoprotein lipase in the peripheral capillary beds, penetrate the fenestrated endothelium in the liver and interact with the hepatocyte cell surface. Hepatic lipase, apoE, and HSPGs together mediate this initial sequestration which takes place in the space of Disse. In a subsequent step, remnants are thought either to interact directly with the LDL receptor (13) or to undergo enrichment with surface-bound apoE which makes them competent to bind to the LRP. The receptorligand complexes are then endocytosed and transported to the lysosomes $(14,15)$.

Because chylomicron remnant uptake by the liver is a such a complex multistep process during which the chylomicron particle sequentially interacts with various lipases, apoproteins, proteoglycans, and receptors, it has proven difficult to demonstrate unequivocally the extent by which LRP contributes under physiological conditions to hepatic remnant metabolism. The strongest indication for a physiologically significant role of LRP in the process stems from gene transfer and knockout experiments in mice. A knockout of the LRP gene itself is not compatible with normal embryonic development and LRP-deficient embryos die early during gestation $(16,17)$. The reason for this lethality presumably lies in the fact that LRP is a multifunctional receptor that binds many biologically diverse ligands, resulting in a pleiotropic developmental phenotype. Fortunately, overexpression (11) and gene inactivation (12) of the receptor-associated protein RAP, a molecular chaperone that tightly binds to LRP and thus prevents the binding of all currently known ligands to the receptor, have provided us with animal models in which hepatic LRP activity is decreased significantly or abolished. The results of these studies are consistent with a scenario in which LRP, in concert with the LDL receptor, mediates the endocytic uptake of chylomicron remnants into the liver. However, because RAP also interacts with other members of the LDL receptor gene family and possibly with other as yet unidentified proteins, a potential participation of receptors other than LRP, such as the postulated lipolysis-stimulated receptor (18), could not be excluded.

To resolve this question we have used inducible tissue-specific gene knockout strategies to selectively destroy the LRP gene in the liver of adult mice expressing or lacking LDL receptors. 


\section{Methods}

Polyinosinic:polycytidylic ribonucleic acid (pI:pC) was purchased from Sigma Chemical Co. (St. Louis, MO). The MX1 cre expression construct (as published in reference 19) was kindly provided by the Rajewsky group (Cologne, Germany). Recombinant adenovirus carrying the Cre gene under the control of the cytomegalovirus promoter (AdCre1) was kindly provided by Drs. Frank Graham and Martina Anton (McMaster University, Hamilton, Ontario, Canada) (20). Cholesterol and triglyceride concentrations were determined enzymatically with assay kits obtained from Boehringer Mannheim (Indianapolis, IN) and Sigma Chemical Co., respectively.

Transgenic animals. Mice in which LRP alleles have been altered by the introduction of loxP sites (referred to as LRP flox/flox or LRP flox $^{\text {) }}$ were generated by homologous recombination of the LRP allele in embryonic stem cells and have been described previously (21). Mice transgenic for the MX1 cre expression construct were generated by pronuclear injection of hybrid $(\mathrm{SJL} \times \mathrm{C} 57 \mathrm{BL} / 6 \mathrm{~J})$ mice $(22)$. Mice from five independent transgenic lines were analyzed by breeding to LRP ${ }^{\text {flox/flox }}$ mice, pI:pC induction of $\mathrm{F}_{1}$ animals carrying the Cre transgene, and determination by Southern blotting of the extent of Cremediated recombination of the floxed LRP allele in the livers of the induced mice. Three lines were highly effective in inducing recombination of the LRP allele in the liver. Of these, line 29-4, which had integrated $\sim 10$ copies of the transgene, was chosen for all subsequent experiments. Induction with $\mathrm{pI}: \mathrm{pC}$ was done by intraperitoneal injection of $250 \mu \mathrm{l}$ of a $1 \mathrm{mg} / \mathrm{ml}$ solution of pI:pC in water. Injections were repeated up to three times in 2-d intervals. Animals were fed regular rodent chow containing 6\% fat (wt/wt) (Teklad Premier Laboratory Diets, Madison, WI).

Virus injections and FPLC analysis of plasma lipoproteins. Recombinant AdCre1 virus for intravenous injection of mice was grown and purified as described previously (21). Animals were anesthetized by intraperitoneal injection of $\mathrm{Nembutal}^{\circledR}(80 \mu \mathrm{g} / \mathrm{g}$ body wt) and a total volume of $150 \mu$ purified virus was injected into the external jugular vein. 10-21 d after virus administration, blood was drawn from the vena cava of the individual animals and $100 \mu l$ plasma was analyzed by FPLC on a Superose 6 column (Sigma Chemical Co.). The cholesterol content of each fraction was determined spectrofluorimetrically as described previously (3).

Immunoblot analysis of membrane proteins and apoproteins. Plasma was collected by retroorbital bleeding before and 10-21 d after virus infection and analyzed by immunoblotting with polyclonal antibodies directed against mouse apoB, apoE, and apoAI $(11,12)$. Membrane proteins were prepared from mouse livers and brains, separated by nonreducing SDS-gel electrophoresis on $4-15 \%$ polyacrylamide gels, and analyzed with polyclonal rabbit antibodies directed against LRP and LDL receptor (21). Bound $\mathrm{IgG}$ was detected using the enhanced chemiluminescence (ECL) system (Amersham, Arlington Heights, IL). Densitometric scanning was performed using an IS-1000 Digital Imaging System 2.0 (Alpha Innotech Corp., San Leandro, CA).

Northern blot analysis. Liver RNA was isolated using the RNeasy system (QIAGEN Inc., Chatsworth, CA) as recommended by the manufacturer. $10 \mu \mathrm{g}$ total RNA was separated on a $1 \%$ formaldehyde gel, transferred to nitrocellulose, and hybridized with $50 \mu \mathrm{Ci}$ ${ }^{32}$ P-labeled probes for LDLR (3) and glyceraldehyde-3-phosphate dehydrogenase (GAPDH) essentially according to Sambrook et al. (23). GAPDH was used as a loading control.

\section{Results}

Liver-specific LRP gene inactivation in adult mice. In a previous study we reported the generation of homozygous mice in which both LRP alleles had been altered by the introduction of loxP sites into intronic and upstream promoter sequences. We demonstrated that recombination of the floxed LRP alleles (and thereby inactivation of the LRP gene) could be

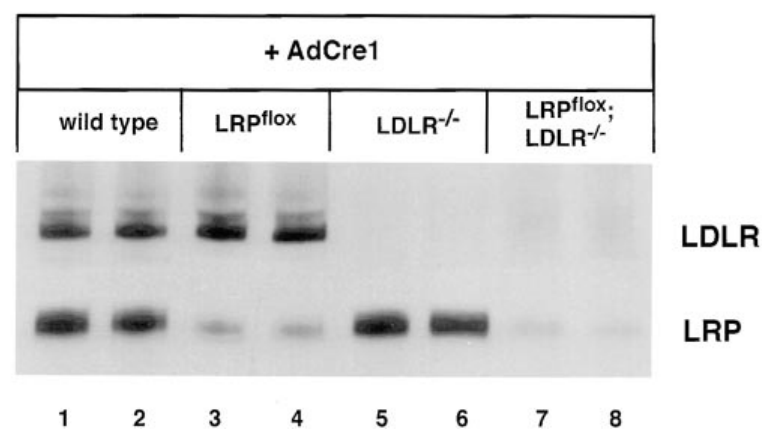

Figure 1. Hepatic expression of LDL receptor and LRP after viral gene transfer of Cre recombinase. Two adult mice of each of the indicated genotypes were injected intravenously with $1.4 \times 10^{12}$ particles of recombinant adenovirus (AdCre1). Liver membrane extracts were prepared $21 \mathrm{~d}$ later. $50 \mu \mathrm{g}$ protein/lane was separated by SDS gel electrophoresis and analyzed by immunoblotting using antibodies directed against the LDL receptor $(L D L R)$ and LRP and the ECL system.

achieved in essentially $100 \%$ of the hepatocytes after intravenous injection of a recombinant adenovirus carrying the Cre recombinase into the animals. Expression of the recombinase led to the excision of the DNA sequences located between the loxP sites and thus to the removal of functionally critical DNA elements and coding sequences from the LRP gene locus (21). Because expression of virally transferred exogenous genes, in this case the Cre recombinase, is almost exclusively limited to the liver (24), LRP inactivation was highly tissue-specific and selective for the liver.

In this study we have used this approach to genetically dissect the physiological role of LRP in hepatic lipoprotein metabolism. We first generated four genetically distinct strains of animals by cross-breeding homozygous LDL receptor deficient mice ( $\mathrm{LDLR}^{-1-}$ ) with animals that were homozygous for the floxed LRP allele (LRP flox/flox). In the second generation, mice that were wild-type at both loci (wt), deficient for the LDL receptor ( $\mathrm{LDLR}^{-1-}$ ), homozygous for the floxed LRP allele (LRPflox/flox), or homozygous for both mutations $\left(\mathrm{LDLR}^{-1-}\right.$; LRP flox/flox were obtained and further propagated by inbreeding. Two animals of each of the four genotypes were intravenously injected with Cre adenovirus (AdCre1) and killed $21 \mathrm{~d}$ later. Liver membrane proteins from the individual animals were separated on a nonreducing SDS gel and analyzed by immunoblotting with antibodies directed against the LDL receptor (LDLR) and the $85-\mathrm{kD}$ subunit of LRP (LRP). Cre expression did not affect hepatic expression levels of LDL receptor and LRP in wild-type animals (21) (Fig. 1, lanes 1 and 2). LRP expression was also not affected in $\mathrm{LDLR}^{-1-}$ mice (Fig. 1, lanes 5 and 6 ). In contrast, LRP expression was greatly reduced in livers from LRP flox/lox mice (21) (Fig. 1, lanes 3 and 4) and in double mutant $\mathrm{LDLR}^{-1-} ; \mathrm{LRP}^{\text {flox/flox }}$ animals (Fig. 1, lanes 7 and 8 ).

Defective remnant removal in $L R P / L D L R$ double knockout animals. To determine the effect of loss of hepatic LRP expression on plasma lipoprotein homeostasis in normal and in LDL receptor-deficient mice, we next compared the plasma concentrations of apolipoproteins B100, B48, E, and AI in wild-type, $\mathrm{LRP}^{\text {flox/flox }}, \mathrm{LDLR}^{-/-}$, and $\mathrm{LDLR}^{-1-} ; \mathrm{LRP}^{\text {flox/flox }}$ mice before (Fig. $2 A$ ) and after AdCre1 injection (Fig. $2 B$ ). In the 
A

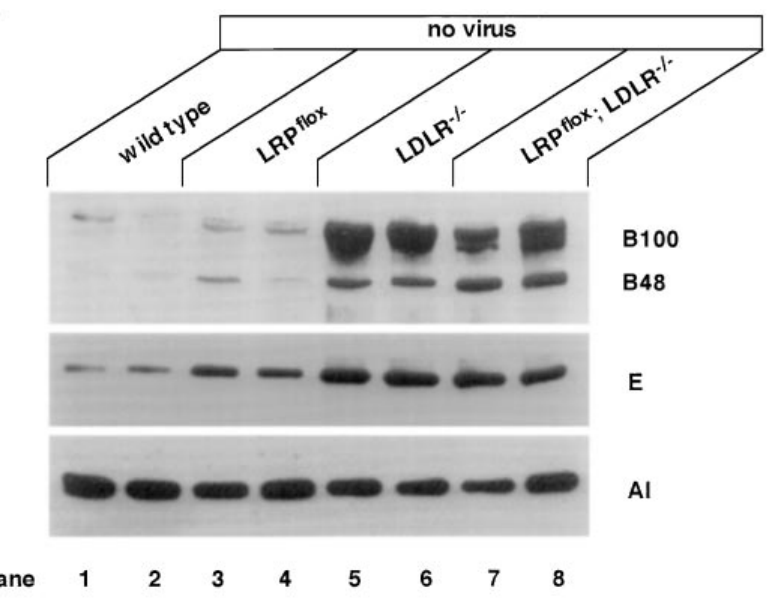

B

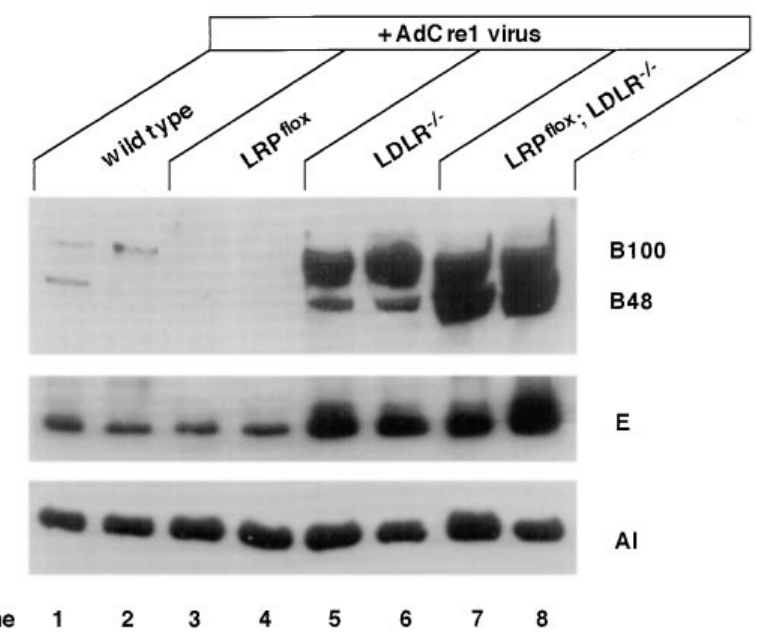

Figure 2. Immunoblot analysis of plasma apoproteins in uninjected $(A)$ and AdCre1-injected $(B)$ mice. Plasma was obtained from two adult mice of each of the indicated genotypes immediately before $(A)$ and $21 \mathrm{~d}$ after injection with $1.4 \times 10^{12}$ AdCre1 viral particles $(B)$. $0.2 \mu$ l plasma was separated by $4-15 \%$ SDS gel electrophoresis and immunoblotted with the indicated polyclonal antibodies against apoB, apoE, and apoAI using the ECL system. The relative position of migration of apoB100, B48, E, and AI is indicated.

absence of Cre virus (Fig. $2 \mathrm{~A}$ ), plasma concentrations of the various apoproteins examined were similar in wild-type (lanes 1 and 2) and LRP floxfflox mice (lanes 3 and 4), and in $\mathrm{LDLR}^{-1-}$ (lanes 5 and 6 ) and LDLR $^{-1-} ;$ LRP $^{\text {flox/flox }}$ animals (lanes 7 and 8 ), respectively. In contrast, after Cre virus administration, apoB 48 concentrations were dramatically increased in $\mathrm{LDLR}^{-1-}$; LRP flox/flox animals (Fig. 2 B, lanes 7 and 8 ) as compared with LDLR $^{-1-}$ mice (lanes 5 and 6 ). apoE concentrations were also slightly increased. In contrast, animals that lack LRP expression in the liver but express LDL receptor normally (Fig. $2 B$, lanes 3 and 4) did not show any significant changes in their plasma apoprotein profiles as compared with wild-type controls that had also received the virus (Fig. $2 B$, lanes 1 and 2).

The dramatic rise in apoB48 concentrations in the double mutant mice that lack functional LRP as well as LDL receptor in their livers was also reflected by the striking change in their plasma cholesterol profile (Fig. 3), as well as total plasma cholesterol and triglyceride concentrations (Table I). In this ex-

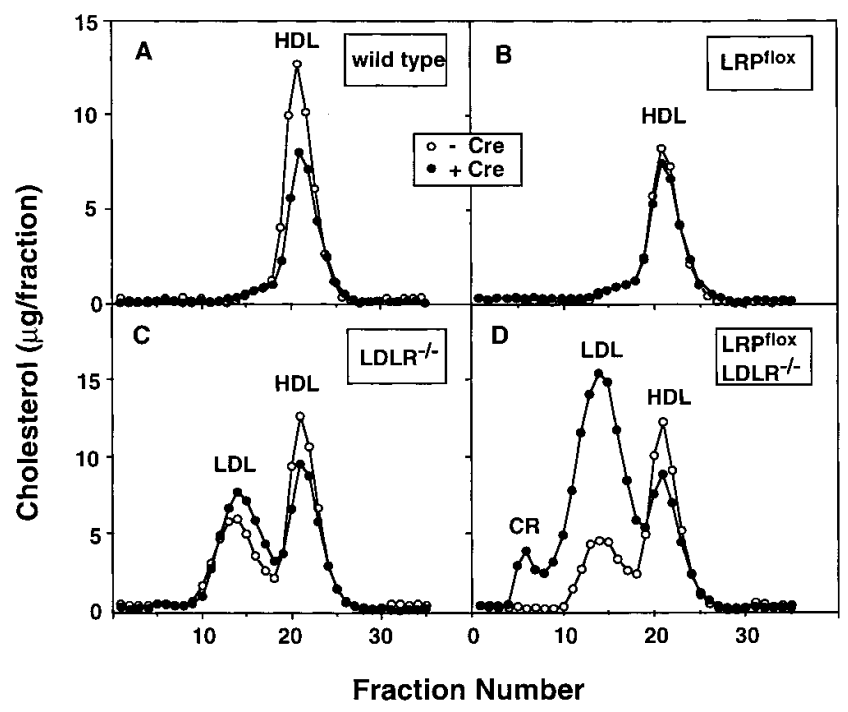

Figure 3. Plasma cholesterol profiles of uninjected (open circles) and AdCre1-injected (closed circles) mice. Plasma was obtained from adult wild-type $(A), \mathrm{LRP}^{\text {flox/flox }}(B), \mathrm{LDLR}^{-/-}(C)$, and $\mathrm{LRP}^{\text {flox/flox; }}$ LDLR $^{-1-}(D)$ mice immediately before (open circles) and $21 \mathrm{~d}$ after injection with $1.4 \times 10^{12}$ AdCre1 viral particles (closed circles). $50 \mu \mathrm{l}$ plasma from each mouse was separated on a Superose 6 FPLC column and cholesterol content of the individual fractions was determined spectrofluorimetrically. The relative positions of remnant lipoproteins $(C R), \mathrm{LDL}$, and HDL are indicated. Shown profiles are the average of profiles obtained from three to four individual animals of the indicated genotype.

periment, animals of the indicated genotype were either not injected (Fig. 3, open circles; Table I, - virus) or injected with AdCre1 (Fig. 3, closed circles; Table I, + virus). Plasma from the indicated number of animals in each group was obtained $21 \mathrm{~d}$ later, individual total plasma lipid concentrations were determined, and plasma from each animal was subjected to FPLC fractionation to separate the lipoproteins by size. AdCre1 injection into $\mathrm{LDLR}^{-/-} ; \mathrm{LRP}^{\text {flloxfllox }}$ animals (Fig. $3 \mathrm{D}$ ) led to a large increase of plasma lipoproteins in the chylomicron remnant/VLDL and LDL size range (closed circles). Total plasma cholesterol as well as triglyceride concentrations were approximately twofold increased as compared with noninjected $\mathrm{LDLR}^{-/-} ; \mathrm{LRP}^{\text {floxfflox }}$ mice or to injected or noninjected LDLR $^{-1-}$ animals (Table I). In neither of the other groups (wild-type, LRP ${ }^{\text {flox/flox }}$, LDLR ${ }^{-1-}$; Fig. 3, A $\Psi$ ) did injection of Cre virus have any reproducible effect on total plasma lipid levels or the plasma cholesterol profile of the animals.

LRP inactivation by pharmacological induction of a Cre transgene. Similar results were obtained in mice in which hepatic expression of Cre recombinase was achieved from an inducible transgene. Transgenic mice carrying Cre under the control of the interferon-inducible MX1 promoter were generated independently using the same construct used to generate the MX1 cre transgenic strain of mice described by Kühn et al. (19). In these animals, Cre is not expressed unless the animals are either injected with interferon or are induced to make interferon. The latter can be achieved by intraperitoneally injecting the animals with pI:pC, a double-stranded synthetic RNA compound that induces peritoneal macrophages to secrete large amounts of interferon which subsequently enters the circulation. The expression profile of the Cre transgene in 
Table I. Total Plasma Cholesterol and Triglyceride Concentrations in AdCre1 Injected or Noninjected Mice of the Indicated Genotypes

\begin{tabular}{lcclll}
\hline & \multicolumn{2}{c}{ Cholesterol (mg/dl) } & & \multicolumn{2}{c}{ Triglycerides (mg/dl) } \\
\cline { 2 - 3 } \cline { 5 - 6 } & + virus & \multicolumn{1}{c}{- virus } & & + virus & - virus \\
\hline Wild-Type & $81 \pm 6(3)$ & $120 \pm 7(9)$ & & $73 \pm 4(3)$ & $42 \pm 10(9)$ \\
LRP flox/flox & $90 \pm 9(4)$ & $118 \pm 28(15)$ & & $77 \pm 10(4)$ & $52 \pm 16(15)$ \\
LDLR $^{-/-}$ & $250 \pm 13(3)$ & $287 \pm 31(5)$ & & $91 \pm 27(3)$ & $86 \pm 28(5)$ \\
LRP floxfllox; & & & & \\
LDLR $^{-/-}$ & $503 \pm 110(4)$ & $234 \pm 27(11)$ & & $185 \pm 47(4)$ & $76 \pm 20(11)$
\end{tabular}

Animals (age $\sim 12 \mathrm{wk}$ ) were intravenously injected with $1.4 \times 10^{12}$ virus particles and the plasma was analyzed $10 \mathrm{~d}$ later. Values shown represent averages from the number of animals per group indicated in parentheses. Variances shown represent standard deviation determined by Student's unpaired $t$ test.

our animals, in particular the kinetics of induction by pI:pC, and tissue specificity of expression were similar to those described in the original article by Kühn and colleagues (19). LRP expression was unaltered in brain after induction of the transgene in double mutant animals (Fig. 4, lanes 1 and 2) compared with non-Cre-transgenic controls (lanes 3 and 4). In contrast, LRP expression in the liver was completely abolished in pI:pC induced MX1 $\mathrm{cre}^{+} ; \mathrm{LDLR}^{-1-} ; \mathrm{LRP}^{\text {flox/flox }}$ animals (Fig. 4 , lanes 5 and 6 ) as compared with identically treated control mice (lanes 7 and 8 ).

In the absence of inducing agent, LRP expression levels (not shown) and lipoprotein profiles (Fig. 5 A, open circles) of $\mathrm{MX} 1 \mathrm{cre}^{+} ; \mathrm{LDLR}^{-/-} ; \mathrm{LRP}^{\text {flox/flox }}$ mice were indistinguishable from $\mathrm{LDLR}^{-1-} ; \mathrm{LRP}^{\text {flox/flox }}$ animals not harboring the MX1 cre transgene. Within $10 \mathrm{~d}$ of transgene induction, however, total plasma cholesterol and triglyceride concentrations were elevated approximately threefold in the MX1 $\mathrm{cre}^{+} ; \mathrm{LDLR}^{-/-} ; \mathrm{LRP}^{\text {flox/flox }}$ animals whereas they were not significantly altered in the nonCre-transgenic controls (Fig. 5 A, closed circles, and Table II). As was the case in the AdCre1-injected double mutant mice, chylomicron remnant/VLDL and LDL lipoprotein fractions

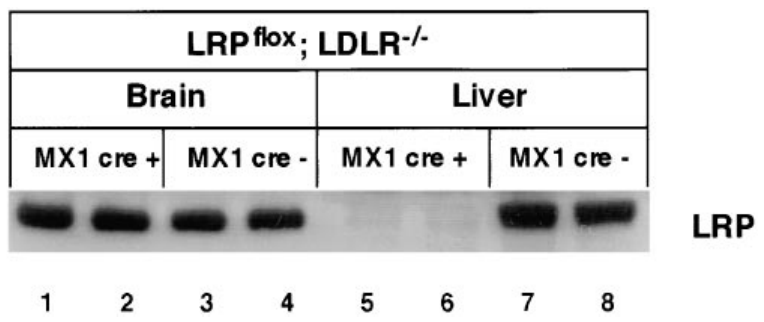

Figure 4. Immunoblot analysis of LRP in brain and liver of MX1 cre transgenic or nontransgenic LRP ${ }^{\text {flox/flox }}$ :LDLR ${ }^{-/-}$mice. Adult $\mathrm{LRP}^{\text {flox/flox}} ; \mathrm{LDLR}^{-1-}$ mice that were either transgenic (lanes 1, 2, 5, and 6) or nontransgenic (lanes 3,4, 7, and 8) for the MX1 cre transgene were injected (three times, intraperitoneally) with $250 \mu \mathrm{g} \mathrm{pI}: \mathrm{pC}$ in 2-d intervals. $10 \mathrm{~d}$ after the last injection, membrane fractions were prepared from livers and brains of the animals and $50 \mu \mathrm{g}$ protein/lane was separated by SDS gel electrophoresis and immunoblotted with an antibody that specifically recognizes the $85-\mathrm{kD}$ subunit of LRP. Bound IgG was detected using the ECL system. were dramatically increased in animals harboring the Cre transgene, but not in nontransgenic controls. Again, a dramatic increase in apoB48 containing lipoproteins was primarily responsible for the elevation of plasma cholesterol and triglyceride levels in pI:pC-induced MX1 $\mathrm{cre}^{+} ; \mathrm{LDLR}^{-1-} ; \mathrm{LRP}^{\text {flox/flox }}$ mice (Fig. $5 \mathrm{~B}$ ). The significant increase in the size of the LDL peak after the induction of the Cre transgene in the $\mathrm{LDLR}^{-1}$; $\mathrm{LRP}^{\text {flox/flox }}$ mice was not due to an accumulation of apoB100 containing "true" LDL particles, but small apoB48 remnant lipoproteins (Fig. $5 A$ ).

$L D L$ receptor upregulation in $L R P$ knockout livers. These findings supported the hypothesis that in the liver LRP and LDL receptor cooperate in removing large cholesterol-rich lipoproteins from the circulation. This raised the possibility that LDL receptor expression might be upregulated in LRPdeficient hepatocytes to compensate for the absence of a functional LRP-mediated removal pathway. To test for such a compensatory regulatory mechanism we compared LDL receptor mRNA (Fig. $6 A$ ) and protein (Fig. $6 B$ ) expression in normal and LDL receptor-deficient mouse livers. Although we did not observe an increase in LDL receptor mRNA levels in LRP-deficient livers (Fig. $6 \mathrm{~A}$, lanes 3 and 4 ) compared with wild-type controls (lanes 1 and 2), the amount of LDL receptor protein expressed was consistently higher when LRP was absent (Fig. $6 \mathrm{~B}$, lanes 3 and 4 ) as compared with wild-type control livers (lanes 1 and 2). Quantitation of LDL receptor mRNA expression on a PhosphorImager and densitometric scanning of the immunoblot revealed no change of LDL receptor mRNA levels, but there was a 2.3-fold increase in LDL receptor protein expression in LRP-deficient livers.

\section{Discussion}

In this study we have used tissue-specific gene knockout approaches to stably inactivate the LRP gene in livers of adult mice. Hepatic LRP expression was virtually abolished after expression of Cre recombinase in this organ. This somatic inactivation of the LRP gene had no obvious negative effects on the apparent general health of the animals, in contrast to the conventional germline disruption of the LRP gene which resulted in early embryonic lethality. However, physiological and biochemical analyses of the animals revealed that LRP-dependent clearance of specific ligands from the circulation by the liver was greatly impaired. These include $\alpha_{2}$-macroglobulin (21) and chylomicron remnants (this study). The current results provide definitive genetic evidence that the endocytic uptake of cholesterol-rich remnant lipoproteins from the circulation by the hepatocytes is achieved by means of a dual receptor system that involves the LDL receptor and the LRP.

We have used two different approaches to express Cre recombinase in the livers of adult mice and thereby specifically inactivate the LRP gene in a temporally and spatially controlled manner: by adenovirus-mediated gene transfer, and by induced expression from an integrated transgene. The first approach relies on the tissue tropism of adenovirus and on the fact that recombinant gene expression from intravenously injected adenovirus is almost exclusively limited to the liver (24). As an independent second approach, and to allay concerns about potential hepatotoxic effects due to viral infection, transgenic mice were generated in which expression of Cre was controlled by the interferon-inducible MX1 promoter (19). Interferon expression was elicited by intraperitoneal injection of 


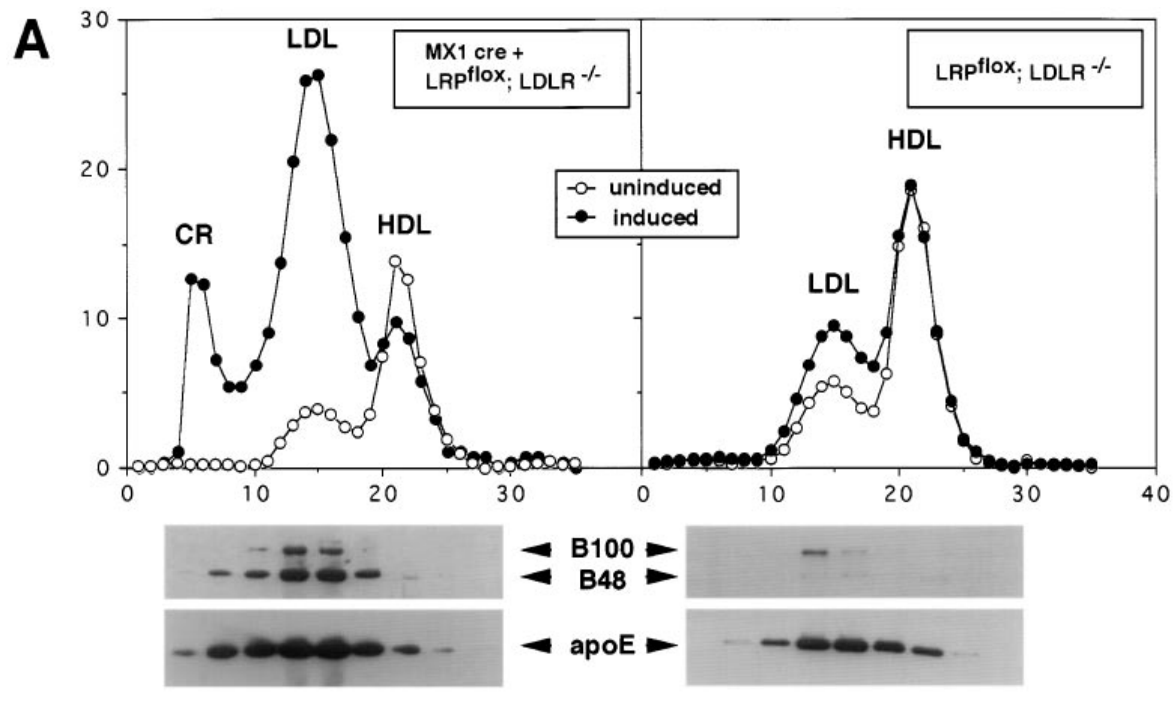

B

\begin{tabular}{|c|c|}
\hline \multicolumn{2}{|c|}{ LRPflox $^{\text {LDLL }}{ }^{-/-}$} \\
\hline MX1 cre - & MX1 cre + \\
\hline
\end{tabular}

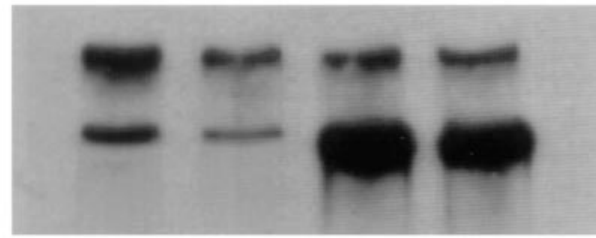

B100

B48
Figure 5. Plasma cholesterol profiles and plasma apoB levels in uninduced and in $\mathrm{pI}$ : pC-induced mice. $(A)$ Adult LRP flox/flox; $\mathrm{LDLR}^{-1-}$ mice that were either transgenic (left) or nontransgenic (right) for the MX1 cre transgene were injected (three times, intraperitoneally) with $250 \mu \mathrm{g} \mathrm{pI}: \mathrm{pC}$ in $2-\mathrm{d}$ intervals. Immediately before the first (uninduced; open circles) and $10 \mathrm{~d}$ after the last injection (induced; closed circles), plasma was obtained from the animals and lipoproteins were size-fractionated on a Superose 6 FPLC column. Cholesterol content of the individual fractions was determined spectrofluorimetrically. The relative positions of remnant lipoproteins $(C R)$, LDL, HDL are indicated. Shown profiles are the average of profiles obtained from two individual animals of the indicated genotype. Immunoblot analyses of corresponding column fractions from induced animals for apoB100, apoB48, and apoE are shown underneath the respective FPLC profiles. $(B)$ Adult $\mathrm{LRP}^{\text {flox/flox}} ; \mathrm{LDLR}^{-/-}$mice that were either nontransgenic (lanes 1 and 2 ) or transgenic for MX1 cre were injected (three times, intraperitoneally) with pI:pC in 2-d intervals. $10 \mathrm{~d}$ after the final injection, $0.2 \mu$ l plasma from each mouse was separated by $4-15 \%$ SDS gel electrophoresis and immunoblotted with a polyclonal antibody against apoB using the ECL system. The relative position of migration of apoB100 and apoB48 is indicated.
pI:pC, a double-stranded RNA polymer that activates and stimulates macrophages to secrete interferons.

Both methods yielded similar results. Hepatic LRP expression was reduced substantially or abolished after adenovirusmediated Cre gene transfer (Fig. 1) or pI:pC induction (Fig. 4). Gene inactivation was limited to tissues accessible to circulating virus or interferons, as no loss of LRP protein expression was observed in virus or interferon-inaccessible tissues such as the brain (Fig. 4) where LRP is also highly expressed (21). In-

Table II. Total Plasma Cholesterol and Triglyceride Concentrations in MX1 Cre Transgenic and Nontransgenic LRP flox/flox; LDLR ${ }^{-1-}$ Mice Injected or Noninjected with pI:pC

\begin{tabular}{|c|c|c|c|c|}
\hline & \multicolumn{2}{|c|}{$\begin{array}{c}\text { Cholesterol } \\
(\mathrm{mg} / \mathrm{dl})\end{array}$} & \multicolumn{2}{|c|}{$\begin{array}{l}\text { Triglycerides } \\
(\mathrm{mg} / \mathrm{dl})\end{array}$} \\
\hline & + pI:pC & - pI:pC & + pI:pC & - pI:pC \\
\hline MX1 cre $^{+} ;$LRP flox/flox; LDLR $^{-/-}$ & 754 & 213 & 274 & 69 \\
\hline LRP $^{\text {flox/flox; }}$ LDLR $^{-1-}$ & 334 & 207 & 131 & 99 \\
\hline
\end{tabular}

Animals (age 16-20 wk) were injected (three times intraperitoneally) with $250 \mu \mathrm{g}$ pI:pC and the plasma from two animals in each group was pooled and analyzed $10 \mathrm{~d}$ after the final injection. activation of the LRP gene in mice that expressed functional LDL receptors did not result in the accumulation of remnant lipoproteins. This was ascertained by immunoblot analysis of plasma apoproteins (Figs. 2 and $5 B$ ), measurement of total plasma lipid concentrations (Tables I and II), and by FPLC size fractionation of plasma lipoproteins (Figs. 3 and $5 A$ ). In contrast, absence of LRP expression in the livers of LDL receptor-deficient mice (3) resulted in an approximately two- to threefold elevation of total plasma cholesterol and triglyceride levels and a dramatic increase of apoB48, a marker for remnant lipoproteins, in plasma (Figs. 2 and $5 \mathrm{~B}$ ). This was also reflected by the substantial increase of cholesterol that was carried in lipoproteins of large (VLDL, CR) and intermediate size (IDL, LDL) in doubly deficient mice (Figs. 3 and $5 A$ ). These findings suggest that both LDL receptor and LRP are involved in the clearance of apoE containing remnants and that the LDL receptor can functionally fully compensate for LRP when the latter has been inactivated by somatic gene disruption (Fig. $3 B$ ).

The increase in cholesterol-rich lipoproteins in the LDL/ IDL size range was due to the accumulation of small apoB48 containing particles (Fig. $5 \mathrm{~A}$ ). These results differ from those obtained in other animal models of defective remnant metabolism, i.e., apoE-deficient mice $(25,26)$, in which the accumulating particles are large and contain relatively more triglyceride. However, important differences exist between the LRP and 
A

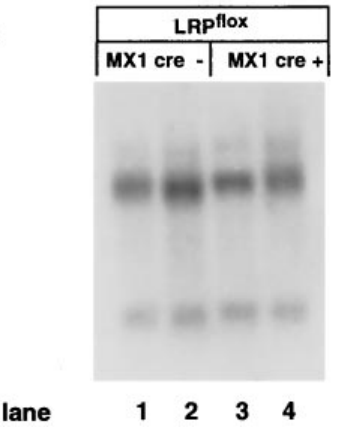

B

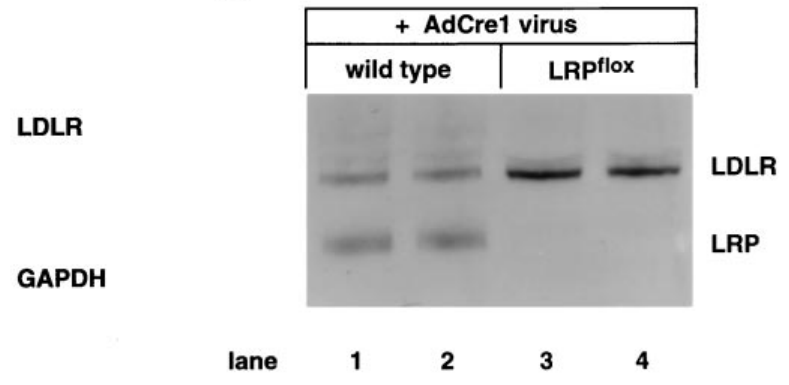

Figure 6. Northern $(A)$ and Western $(B)$ blot analyses of LDL receptor expression in wild-type and LRP-deficient livers. $(A)$ Total mouse liver RNA from MX1 Cre transgenic (lanes 3 and 4 ) or nontransgenic mice (lanes 1 and 2) that had been induced with pI:pC was obtained $21 \mathrm{~d}$ after the final injection. $10 \mu \mathrm{g}$ of each sample was analyzed by Northern blotting using ${ }^{32} \mathrm{P}$ labeled probes specific for the mouse LDL receptor $(L D L R)$ or GAPDH. Filters were exposed to Kodak XAR film for $16 \mathrm{~h}$ at $-80^{\circ} \mathrm{C}$. (B) Wild-type (lanes 1 and 2 ) or LRP flox/flox mice (lanes 3 and 4 ) were in-

jected with AdCre1 and liver membrane were prepared $21 \mathrm{~d}$ later. $50 \mu \mathrm{g}$ of liver membrane protein extract/lane was separated by $4-15 \%$ SDS gel electrophoresis, transferred to nitrocellulose membranes, and incubated with antibodies directed against the 85-kD subunit of LRP or the LDL receptor $(L D L R)$. Bound $\mathrm{IgG}$ was detected using the ECL system.

the apoE knockout models. In apoE knockout mice the composition of the lipoprotein particles is altered due to the absence of apoE. Instead, the particles contain significant amounts of apoAIV. This change in apoprotein composition might affect the susceptibility of the chylomicrons to lipolytic processing and account for the observed differences in the make-up of the remnants.

In the mouse, substantial amounts of apoB48 are produced by the liver, in contrast to humans where this apoprotein is almost exclusively made by the intestine (27-29). The apoB48 containing remnants that accumulate in double knockout animals must therefore constitute a mixture derived from synthesis in both organs.

If both LRP and LDL receptor are equally effective in mediating the clearance of remnant lipoproteins in the liver, why is there no discernible accumulation of remnants in the circulation when either LRP or LDL receptor is functionally inactivated? One answer to these questions has been offered by the combined studies of Hamilton and Havel $(8)$, Ji et al. $(6,7)$, and Mortimer et al. (9) who demonstrated that apoE in conjunction with HSPGs leads to sequestration of remnants on the hepatocyte surface and their subsequent uptake by an apoE-dependent secretion/recapture mechanism (30). Taken together, these studies suggest that remnant uptake by the liver involves a two-stage process in which circulating remnant particles are quickly removed from the bloodstream by a nonreceptor-mediated interaction with apoE on the hepatocyte surface, followed by enrichment with apoE and subsequent internalization by the LDL receptor and by LRP. In this model, remnant lipoproteins would only start to accumulate in the circulation after the sequestration compartment has been saturated.

Another reason why remnants do not accumulate when LRP alone has been knocked out in the liver has been offered by our finding that LDL receptor protein expression is increased in these animals (Fig. $6 \mathrm{~B}$ ). Because LDL receptor protein but not mRNA expression is increased, this compensatory mechanism is likely to take place at the posttranscriptional level, possibly by increasing receptor half-life. The increase of LDL receptor expression also suggests that under normal physiological conditions LRP contributes substantially to hepatic remnant clearance and does not merely serve as a backup receptor that has meaningful clearance functions only when the LDL receptor is absent.
Another unexpected observation has resulted from the present experiments. In a previous study (11), we used adenoviral transfer of the inhibitory protein RAP to completely prevent the binding of remnants to LRP. In these experiments we noted a large increase in the plasma concentration of cholesterol and triglycerides that were carried in apoB48 containing lipoprotein particles resembling remnants. In this study we also observed a marked increase in plasma cholesterol and apoB48 concentrations, but a much smaller increase in plasma triglyceride levels compared with the RAP overexpression experiments. This was true irrespective of whether LRP gene disruption was induced by adenoviral transfer of Cre or by induction of the recombinase from the integrated transgene, excluding the possibility of a hepatotoxic nonspecific viral effect. The most likely explanation for the observed quantitative difference between these two conceptually different experimental approaches is that RAP, when it circulates at high concentrations in the bloodstream, not only prevents remnant removal by LRP in the liver, but may also interfere with other receptors or biochemical processes that participate in the catabolism of chylomicrons and remnants. Future studies should identify this unknown RAP-sensitive step and determine whether a postulated lipolysis-stimulated receptor (18) might play a role in this pathway.

Taken together, these experiments provide unequivocal genetic evidence for a physiological role of LRP in the hepatic uptake of remnant lipoproteins and in the maintenance of plasma lipid homeostasis. They also demonstrate the feasibility of genetically dissecting and analyzing complex and developmentally essential biochemical pathways by temporally and spatially controlled somatic gene inactivation. By combining different tissue-specific promoters and a ligand-inducible Cre recombinase (31) it should be possible to elucidate the role of LRP or other essential genes for embryonic development as well as for neuronal development and survival and the formation of atherosclerotic lesions.

\section{Acknowledgments}

We are indebted to Martina Anton and Frank Graham for sharing the Cre-expressing adenovirus, to Wen-Ling Niu, Laura Quinlivan, and Scott Clark for outstanding technical assistance, and to Mike Brown, Joe Goldstein, and David Russell for critical reading of the manuscript. 
This work was supported by grants from the National Institutes of Health (HL-20948), the Keck Foundation, the Howard Hughes Medical Institute, and the Perot Family Foundation. A. Rohlmann was supported by a fellowship from the Deutsche Forschungsgemeinschaft and M. Gotthardt by the Boehringer Ingelheim Fonds. J. Herz is an Established Investigator of the American Heart Association and Parke-Davis Company.

\section{References}

1. Goldstein, J.L., and M.S. Brown. 1989. Familial hypercholesterolemia. In The Metabolic Basis of Inherited Disease. C.R. Scriver, A.L. Beaudet, W.S. Sly, and D. Valle, editors. McGraw-Hill Publishing Co., New York. 1215-1250.

2. Rubinsztein, D.C., J.C. Cohen, G.M. Berger, D.R. van der Westhuyzen, G.A. Coetzee, and W. Gevers. 1990. Chylomicron remnant clearance from the plasma is normal in familial hypercholesterolemic homozygotes with defined receptor defects. J. Clin. Invest. 86:1306-1312.

3. Ishibashi, S., M.S. Brown, J.L. Goldstein, R.D. Gerard, R.E. Hammer, and J. Herz. 1993. Hypercholesterolemia in LDL receptor knockout mice and its reversal by adenovirus-mediated gene delivery. J. Clin. Invest. 92:883-893.

4. Kita, T., J.L. Goldstein, M.S. Brown, Y. Watanabe, C.A. Hornick, and R.J. Havel. 1982. Hepatic uptake of chylomicron remnants in WHHL rabbits: a mechanism genetically distinct from the low density lipoprotein receptor. Proc. Natl. Acad. Sci. USA. 79:3623-3627.

5. Shafi, S., S.E. Brady, A. Bensadoun, and R.J. Havel. 1994. Role of hepatic lipase in the uptake and processing of chylomicrons remnants in rat liver. J. Lipid. Res. 35:709-720.

6. Ji, Z.S., S. Fazio, Y.L. Lee, and R.W. Mahley. 1994. Secretion-capture role for apolipoprotein $\mathrm{E}$ in remnant lipoprotein metabolism involving cell surface heparan sulfate proteoglycans. J. Biol. Chem. 269:2764-2772.

7. Ji, Z.-S., S.J. Lauer, S. Fazio, A. Bensadoun, J.M. Taylor, and R.W. Mahley. 1994. Enhanced binding and uptake of remnant lipoproteins by hepatic lipase-secreting hepatoma cells in culture. J. Biol. Chem. 269:13429-13436.

8. Hamilton, R.L., J.S. Wong, L.S.S. Guo, S. Krisans, and R.J. Havel. 1990. Apolipoprotein E localization in rat hepatocytes by immunogold labeling of cryothin sections. J. Lipid Res. 31:1589-1603.

9. Mortimer, B.C. D.J. Beveridge, I.J. Martins, and T.G. Redgrave. 1995. Intracellular localization and metabolism of chylomicron remnants in the livers of low density lipoprotein receptor-deficient mice and apoE-deficient mice. Evidence for slow metabolism via an alternative apoE-dependent pathway. $J$. Biol. Chem. 270:28767-28776.

10. Herz, J., U. Hamann, S. Rogne, O. Myklebost, H. Gausepohl, and K.K. Stanley. 1988. Surface location and high affinity for calcium of a 500-kd liver membrane protein closely related to the LDL-receptor suggest a physiological role as lipoprotein receptor. EMBO (Eur. Mol. Biol. Organ.) J. 7:4119-4127.

11. Willnow, T.E., Z. Sheng, S. Ishibashi, and J. Herz. 1994. Inhibition of hepatic chylomicron remnant uptake by gene transfer of a receptor antagonist. Science. 264:1471-1474.

12. Willnow, T.E., S.A. Armstrong, R.E. Hammer, and J. Herz. 1995. Functional expression of low density lipoprotein receptor-related protein is controlled by receptor-associated protein in vivo. Proc. Natl. Acad. Sci. USA. 92: 4537-4541.

13. Choi, S.Y., and A.D. Cooper. 1993. A comparison of the roles of the low density lipoprotein (LDL) receptor and the LDL receptor-related protein $/ \alpha_{2}-$ macroglobulin receptor in chylomicron remnant removal in the mouse in vivo. J. Biol. Chem. 268:15804-15811.

14. Herz, J., S.Q. Qiu, A. Oesterle, H.V. DeSilva, S. Shafi, and R.J. Havel. 1995. Initial hepatic removal of chylomicron remnants is unaffected but en docytosis is delayed in mice lacking the low density lipoprotein receptor. Proc. Natl. Acad. Sci. USA. 92:4611-4615.

15. Mokuno, H., S. Brady, L. Kotite, J. Herz, and R.J. Havel. 1994. Effect of the 39-kD receptor-associated protein on the hepatic uptake and endocytosis of chylomicron remnants and low density lipoproteins in the rat. J. Biol. Chem. 269:13238-13243

16. Herz, J., D.E. Clouthier, and R.E. Hammer. 1992. LDL receptor-related protein internalizes and degrades uPA/PAI-1 complexes and is essential for embryo implantation. Cell. 71:411-421.

17. Herz, J., D.E. Clouthier, and R.E. Hammer. 1993. Correction: LDL receptor-related protein internalizes and degrades uPA-PAI-1 complexes and is essential for embryo implantation. Cell. 73:428.

18. Yen, F.T., C.J. Mann, L.M. Guermani, N.F. Hannouche, N. Hubert, C.A. Hornick, V.N. Bordeau, G. Agnani, and B.E. Bihain. 1994. Identification of a lipolysis-stimulated receptor that is distinct from the LDL receptor and the LDL receptor-related protein. Biochemistry. 33:1172-1180.

19. Kühn, R., F. Schwenk, M. Aguet, and K. Rajewsky. 1995. Inducible gene targeting in mice. Science. 269:1427-1429.

20. Anton, M., and F.L. Graham. 1995. Site-specific recombination mediated by an adenovirus vector expressing the Cre recombinase protein: a molecular switch for control of gene expression. J. Virol. 69:4600-4606.

21. Rohlmann, A., M. Gotthardt, T.E. Willnow, R.H. Hammer, and J. Herz. 1996. Sustained somatic gene inactivation by viral transfer of Cre recombinase. Nat. Biotech. 14:1562-1565.

22. Hogan, B., R. Beddington, F. Constantini, and E. Lacy. 1994. Manipulating the Mouse Embryo: A Laboratory Manual. Cold Spring Harbor Laboratory Press, New York. 497 pp.

23. Sambrook, J., E.F. Fritsch, and T. Maniatis. 1989. Molecular Cloning: A Laboratory Manual. Cold Spring Harbor Laboratory Press, New York.

24. Herz, J., and R.D. Gerard. 1993. Adenovirus-mediated transfer of low density lipoprotein receptor gene acutely accelerates cholesterol clearance in normal mice. Proc. Natl. Acad. Sci. USA. 90:2812-2816.

25. Plump, A.S., J.D. Smith, T. Hayek, K. Aalto-Setälä, A. Walsh, J.G. Verstuyft, E.M. Rubin, and J.L. Breslow. 1992. Severe hypercholesterolemia and atherosclerosis in apolipoprotein E-deficient mice created by homologous recombination in ES cells. Cell. 71:343-353.

26. Zhang, S.H., R.L. Reddick, J.A. Piedrahita, and N. Maeda. 1992. Spontaneous hypercholesterolemia and arterial lesions in mice lacking apolipoprotein E. Science. 258:468-471.

27. Havel, R.J., and J.P. Kane. 1989. Structure and metabolism of plasma lipoproteins. In The Metabolic Basis of Inherited Disease. C.R. Scriver, A.L. Beaudet, W.S. Sly, and D. Valle, editors. McGraw-Hill, New York. 1129-1138.

28. Chan, L. 1992. Apolipoprotein B, the major protein component of triglyceride-rich and low density lipoproteins. J. Biol. Chem. 267:25621-25624.

29. Scott, J. 1989. The molecular and cell biology of apolipoprotein-B. Mol. Biol. Med. 6:65-80.

30. Brown, M.S., J. Herz, R.C. Kowal, and J.L. Goldstein. 1991. The lowdensity lipoprotein receptor-related protein: double agent or decoy? Curr. Opin. Lipidol. 2:65-72.

31. Feil, R., J. Brocard, B. Mascrez, M. LeMeur, D. Metzger, and P. Chambon. 1996. Ligand-activated site-specific recombination in mice. Proc. Natl. Acad. Sci. USA. 93:10887-10890. 